\title{
THE AUXILIARY + INFINITIVE CONSTRUCTION IN HUNGARIAN*
}

\author{
GÁBOR TOLCSVAI NAGY \\ Department of Hungarian Linguistics \\ Eötvös Loránd University \\ Múzeum krt. 4/a \\ $\mathrm{H}-1088$ Budapest \\ Hungary \\ tnghu@hotmail.com
}

\begin{abstract}
This paper gives a descriptive overview of the prototypical Hungarian auxiliary+ infinitive construction, discussed in the framework of functional cognitive grammar worked out by Ronald Langacker and in the grammaticalization theory for auxiliaries by Bernd Heine. The degree of grammaticalization seems to have a greater role in the construction than suggested in the previous literature, while Langacker's theory (fit for English) needs some modification. In the construction discussed here, the auxiliary profiles a process, and (future) tense or modality. The infinitive accounts for most of the semantic content of the overall event structure. Both component structures contribute equally to the profile of the construction (the composite structure), in a complementary way, in contrast with a prototypical composite structure. I assume that the Hungarian auxiliary serves the function of imposing temporality on a nontemporal infinitive, and also that of the grounding predication, which marks a departure from Langacker's English model. The Hungarian grounding predication (the auxiliary) and its head (the infinitive) do not belong to the same grammatical class, only the auxiliary + infinitive composite structure construes a process temporally. Also, degrees of subjectification contribute to types of construal, yielding a dimension of variation that cannot be derived from the deontic/epistemic distinction. Just like the semantic functions of the auxiliaries, subjectification and grounding show gradual characteristics.
\end{abstract}

Keywords: auxiliary, infinitive, composite structure, profile determinacy, subjectification, grounding

* I would like to express my thanks to the reviewers for their extensive comments. I am also grateful for the help and suggestions of Péter Pelyvás, Nóra Kugler, Mária Ladányi and András Imrényi. 


\section{Introduction}

The schematic concept of a process is a structured one. On the one hand, it contains the process semantically, construed objectively, in a way reflected by the event structure with its relational and temporal profile and associated schematic participants. On the other hand, the finite verb anchors this semantically construed process to the conceptualizers (mainly the speaker and the hearer) and to the spatio-temporal context of their discourse, making the denoted process identifiable, i.e., epistemically grounded in the current discourse space. In Hungarian, this complex semantic content may take various forms of expression.

The Hungarian auxiliary + infinitive construction is discussed here in the framework of Langacker's cognitive grammar (Langacker 1987), and Heine's theory of grammaticalization (Heine 1993). Partly as a result of this background, my approach will differ in a significant way from earlier Hungarian descriptions by taking a predominantly semantic perspective on the construction. The two basic suggestions I will make are the following:

(1) As a default case, the Hungarian auxiliary + infinitive construction, grounded within a clause, has the same or similar semantic and syntactic functions as a single finite verb. The auxiliary and the infinitive form a linguistic unit, analysable as a composite structure (as defined by Langacker 1987, 58-9). However, the construction differs from prototypical composite structures in that its component structures have shared, complementary contributions to the profile of the complex unit. Furthermore, the grounding predication (the auxiliary) and the grounded infinitive do not belong to the same grammatical class, in contrast with Langacker's clausal grounding theory (Langacker 1991, 248). These linguistic units are construed by the use of event schemas (cf. Heine 1993, $30-1)$.

(2) Auxiliaries in Hungarian have evolved through a grammaticalization process whereby certain verbs came to acquire highly abstract meanings in complex, periphrastic constructions. The semantic functions of the auxiliaries, as well as subjectification and grounding, show gradual characteristics. There is no auxiliary + lexical verb structure in this case, as main verbs participate in the composite structure as infinitives, in a derived form, with a non-prototypical verbal semantic content.

Examples in (3) illustrate some of the features summarized in (1) and (2):

Acta Linguistica Hungarica 57, 2010 
(3)
(a) Esik az eső.
fall-pres.ind.3sg the rain
'It is raining.'
(b) Esni fog az eső. fall-inf will.3sg the rain 'It will be raining.'

In the sections to follow, I will first introduce the theoretical framework to be adopted $(\mathbf{2})$. In sections $\mathbf{3 - 9}$, various facets of the construction will be explored: the diverse ways of construing a process in Hungarian (3), the basic morphosemantic types of the auxiliary + infinitive construction (4), the semantics of the Hungarian infinitive (5), the semantics of the Hungarian auxiliary $(\mathbf{6})$, the Hungarian auxiliary + infinitive construction as a linguistic unit ( $\mathbf{7})$, its submorphemic structure $(\mathbf{8})$, and the variability of subjectification and grounding for modality $(\mathbf{9})$.

\section{The theoretical framework}

The present paper adopts a functional cognitive linguistic framework. The main points of this framework are as follows (see, e.g., Langacker 1987; Barlow-Kemmer 2000; Geeraerts-Cuyckens 2007). The prototype principle: membership in a category is a matter of degree, members are added to a category by shared properties and family resemblance obtained via experience, categories have no clear-cut boundaries. The role of construal and perspectivization: in the process of cognition one construes (i.e., processes through analyzing comprehension) the experienced phenomena, and uses the resulting conceptual structures as semantic structures in linguistic expressions, always from a specific conceptual perspective. The usage-based description of language: production and comprehension are inherent factors of the linguistic system; also, there is no strict distinction between the synchronic and the diachronic aspects of language. The dynamic nature of language.

The general literature on auxiliaries cannot be surveyed here, it is summarized critically in Heine (1993), and in Anderson (2006). Within the cognitive theoretical framework, the main points of Langacker's explanation of the auxiliary are as follows. The verb designates a process as a type. This process is grounded by tense, with reference to the time of the speech event; and modally, in relation to the reality established by the interlocutors. The clause describes a scene, a situation with participants, profiling a process. The scene is construed objectively in so far as it is explicitly expressed as the focus of attention, it is "onstage". Any entity, e.g., the speaker (or any other conceptualizer) is construed subjectively, 
"offstage", as "an implicit, unselfconscious subject of conception [...] being totally absorbed in apprehending the onstage situation" (Langacker $2006,18)$. An objectively construed entity may be subjectified and vice versa.

In English, the main verb is the content verb, expressing the core semantic content and profiling the process as a type, whereas the inflectional morphemes (-en, -ing) and the auxiliary verbs impose a particular construal on the content verb.

\begin{abstract}
"The affixal/inflectional member in each case combines with a verb and derives an atemporal relation [...] The associate schematic verb (have or be) is then available to impose its own processual profile on the atemporal relation, creating another verb at a higher level of conceptualization. [...] The grounded verb is the one that imposes its processual profile in the final cycle (at the highest level of organization). Either have or be functions as the grounded verb, depending on which pairs of auxiliary elements are chosen. If none is chosen, the grounded verb and the content verb (V) are the same."

(Langacker 1991, 199-200)
\end{abstract}

Clausal grounding is accomplished e.g., by tense morphemes -s, -ed, and modal auxiliaries like may, will, should, modals being the first element in the auxiliary chain: they take the entire clausal head as their complements. There is a close correspondence between the modal and the head:

"A grounding predication and its head must represent the same grammatical
class (as determined by their profiles); for clauses, each must be processual.
Thus, because an infinitive or participle is atemporal, the complement of a
modal must be a simple verb."
(ibid., 248)

Grounding relates the designated process to the speaker's position in different degrees of epistemic distance from the immediate known reality. The markers of present and past belong to the domain of reality as well as morphemes for person and number, whereas a modal places the designated process in the region of irreality.

The modal auxiliary highlights the presence of a certain potency or force, directed at the trajector (typically the grammatical subject) of the clause, in a force-dynamic relation. This modal force is not in the focus of attention and unprofiled (it is offstage); i.e., it is construed subjectively, in contrast with the profiled process expressed by the content (main) verb, construed objectively. The source of modal force or potency is the speaker or some other source related to the ground (the immediate scope of the discourse space), cf. Langacker (1991, 271; 2006, 19-21).

Acta Linguistica Hungarica 57, 2010 
The basic notions of Langacker's model are highly relevant for the description of the Hungarian auxiliary + infinitive construction. However, the more detailed model elaborated for the English auxiliary cannot be applied to Hungarian without some modifications. Though the Hungarian infinitive is atemporal, and both auxiliaries and infinitives can be grounded by morphemes for tense, person and number in different ways, the auxiliary verb is nevertheless a grounding predication, with room for variation within the class (see section 9). The nature of construal (particularly with respect to semantic correspondences and profile determinacy), the degree at which Hungarian auxiliaries have been grammaticalized in Heine's sense (see section 6), and the degree of subjectivity involved seem to be the crucial factors to be examined.

Most recent descriptions in Hungarian linguistics, although they may differ in theoretical and methodological respects, seem to agree that the auxiliary + infinitive construction is describable in morphosyntactic terms without essential reference to the semantic side (see Keszler 2000, 72ff, 252ff in a traditional, and É. Kiss 2002, 205-20; 2004 in a generative framework). For Kálmán et al. (1986), the key diagnostic property of auxiliaries is that they are unstressed in a structure with infinitives, in sentences with a flat prosody. Pelyvás (1998), accepting the results of Kálmán et al., analyses the grounding features of Hungarian modals, cf. also Pelyvás (2006).

\section{Ways of construing a process temporally in Hungarian}

A temporal relation can be expressed by various types of schematic structure in Hungarian, including: (a) a finite verb, (b) an auxiliary + infinitive construction, (c) a verb or copula + nominal or adjective construction. The differences of these categories expressing a temporal relation are only scalar. The following section discusses the morphosemantic properties of each type of construction.

As in other languages, the schematic semantic structure of a prototypical Hungarian verb construes a process, a temporal relation between two schematic participants, with the sequential scanning of subsequent momentary states (Langacker 1987, 248-53). The verb is semantically dependent: a process cannot be conceptualized without the conceptualization of its participants. The temporal relationship has an event structure, 
and it is represented by a sequence of consecutive states, through sequential scanning (cf. idem.). On a higher level of abstraction, these semantic structures are instantiations of event schemas, with verbs instantiating abstract event schemas like action, motion, change of state, location, etc. (Heine 1993, 31). The participants are conceptualized only schematically in the semantic structure of the verb. One of the participants, the trajector is usually more prominent than the other (the landmark or secondary figure). Figures (participants) are denoted and elaborated by nominals, which stand in partial correspondence relations (valence relations) with the verb. Nominals are related to the verb compulsorily by case suffixes in Hungarian. The verb determines the profile of the clause, as a component part of its semantic structure. The process profiled by the verb is grounded, the speaker and the hearer are able to identify or negotiate how the process type is instantiated in the current discourse space.

The Hungarian finite verb is obligatorily inflected for tense (formally present and past), mood (indicative, imperative, conditional), person (1st, 2nd, 3rd) and number (singular, plural), and definiteness (the definite or indefinite status of the $3 r d$ person object, if there is any); i.e., a single finite verb cannot stand in its stem form, as a mere lexical item. These inflectional morphemes form complete paradigms. In other words: the Hungarian finite verb is grounded epistemically for tense, mood, person and number, and also for the definiteness of the grammatical object. There are no one-to-one form-function correspondences, as not every morphological function has its own unique signifier. Rather, a complex submorphemic system prevails, where suffixation, root modification, and zero suffixing all occur in certain combinations, depending on the morphophonological properties of both the stem and the affix. Almost every form of temporal and many forms of modal content may be expressed by one complex finite verbal form, even those which are usually denoted by an auxiliary + infinitive construction. For example, present tense may indicate future time reference, and the modal domains of possibility and permission may be signalled by the derivational suffix - hat.

Compared to a prototypical verb, the Hungarian auxiliary + infinitive construction expresses a process in a partially different way, considering both its morphological/semantic structure and epistemic grounding. In contrast with the specific meaning of the verb, the auxiliary encodes (future) tense or modality, and processual meaning in a highly schematic way. Of the tenses, future is expressed by an auxiliary, present and past by the usual suffixes on certain modal auxiliaries. In default instantia- 
tions of the auxiliary + infinitive construction, person and number need not be explicitly and unambigously marked, but it is possible to mark them in many cases. Only a subset of auxiliaries can be inflected for the (in)definiteness of the object (akar 'want', fog 'will, shall').

A further type of expression denoting a process (temporal relation) is the verb or copula + nominal or adjective construction. It belongs to the same general type as its nominal or even adjectival component has a highly abstract processual content or conceptual base. The verb or copula, for their part, have a full verbal paradigm, denoting abstract action, existence or state. These constructions fall beyond the scope of this paper (but see Modrián-Horváth 2009).

\section{The basic variants of the Hungarian auxiliary + infinitive structure}

Four characteristic morphosyntactic types of the Hungarian auxiliary + infinitive structure can be differentiated:

(A) Auxiliary expressing modality (directly) and tense (with suffixes) + infinitive:

(4) Enni kell.

eat-inf must.pres.ind.3sg

'Everybody must eat./You must eat./We must eat.'

(5) Itt lehetett úszni.

here may-pst swim-inf

'One was allowed to swim here.'

(B) Auxiliary expressing modality (directly) and tense (with suffixes) + infinitive grounded by person and number:

(6) Mennem kell.

go-inf-1sg must.pres

'I must go.'

(7) Menned kellett.

go-inf-2sg must-pst

'You had to go.' 
(C) Auxiliary grounded by person and number, inflected for tense (formally present, with future time reference) + infinitive:

(8) A karácsony el fog jönni. the Christmas prev will.3sg come-inf 'Christmas will come.'

(9) Holnap is fogtok dolgozni. tomorrow also will-2pl work-inf 'You will work tomorrow, too.'

(D) Auxiliary grounded by tense, mood, person and number + infinitive:

(10) A madár tud repülni. the bird can.pres.ind.3sg fly-inf 'Birds can fly'

(11) A nyolcévesek tudtak olvasni. the eight-year-olds can-pst.ind-3pl read-inf 'The eight-year-olds were able to read.'

The semantic content of the components will be elaborated on in section 7.

\section{The semantics of the Hungarian infinitive}

The infinitive in Hungarian is a linguistic unit of two component structures: one is the verbal root, the other is the derivational suffix $-n i$ of the infinitive.
live live-inf
to live
(12) (a) él - élni
(b) megy - menni
go go-inf
to go

This is a composite structure consisting of two semantic component structures, the verbal one being detailed (more specific), the suffix highly schematic. When followed by the infinitive suffix, the verbal root of the infinitive is often modified morphophonologically (as in (12b)), thus the internal structure of the infinitive is less transparent, while its linguistic 
unit status is reinforced. As a consequence, the infinitive differs substantially from the original verb. The Hungarian infinitive as a composite structure exhibits the following properties:

- it denotes a relation in an event atemporally;

- it maps the relation in the event with summary scanning, as simultaneous activation: "[w] hile the states are still accessed in their natural sequence, they undergo summation: that is, they are mentally superimposed [...] at each moment $\mathrm{T}_{i}$ of processing time, the focused conception comprises all the configurations thus far encountered in scanning" (Langacker 2008, 111; see also Langacker 1987, 248-53). This successive yet cumulative, atemporal way of processing, which I take to be characteristic of the Hungarian infinitive is a transitional type between prototypical sequential and summary scanning. Pelyvás $(2006,128)$ analyses the infinitive in a similar way, though his account relies on the notion of reduced sequential processing;

- the event structure scanned in summary fashion and the landmark are profiled within the semantic structure of the infinitive;

- semantically it is dependent: it has an elaboration site for temporality (its conceptual base), and also for the schematic landmark (cf. van valaki valahol 'somebody is somewhere' vs. lenni valahol 'to be somewhere'); the trajector can be involved schematically only in structures suffixed for person and number (see section $\mathbf{9}$ ).

The component items of the Hungarian infinitive (functioning via their semantic relations) can receive the following characterizations:

- the verbal root: it expresses a schematic event structure, with summary scanning, without denoting a process and without epistemic grounding (the metonymic shift of attention, compared to the verb, is the result of the derivational suffix);

- the -ni derivational suffix: its function is the modification of the semantic content of the verb by attention shift from processual aspects towards a more nominal (thing-like) semantic profile.

Besides auxiliaries, the Hungarian infinitive can be grounded by suffixes for person and number; suffixes for tense and mood are not allowed. The suffixes for person and number are not verbal but possessive ones, thus supporting the semantic shift from the verblike towards the nounlike.

There are significant semantic differences between the verb and the noun, although the meanings of certain nouns (e.g., fire, flood, motion) appear to show more similarities to verbs than to nouns denoting physical objects. Also, some verbs may be judged to be more dynamic (e.g., the motion verbs), while others more static (such as the state verbs). Hopper and Thompson (1985) point out that the prototypical verb and the 
prototypical noun are in the greatest semantic contrast. Although verbs, infinitives and nouns may express very similar conceptual contents, verbs impose a stronger temporal profile on these than corresponding infinitives or nouns do. Compare, for instance, the way the following lexical units express the notion of quick human motion: futok 'I run/I am running' (verb) - futni 'to run' - futás 'running' (this latter word is a noun directly formed from the verb root with a frequent deverbal derivational suffix).

Hopper and Thompson (1985) assume that the categorial distinction between verbs and nouns, as well as the degree of eventhood (i.e., the processual and temporal properties of the expressed event) are motivated by informational demands. Degree of eventhood is motivated first of all by the temporal content of the verb and its properties. The overt expression of temporality may reduce if the verb designates an event that is less important for discourse information. The semantic structure of the Hungarian infinitive as an intermediate category on the verb-noun conceptual continuum has process-like and object-like properties at the same time, but it differs significantly from both the verb and the noun.

\section{The semantics of the Hungarian auxiliary}

The category of Hungarian auxiliaries is a fine example of prototype effects: one finds both central and peripheral auxiliaries, with certain co-occurring properties developing into clusters. Also, the Hungarian auxiliary occupies a transitional domain between the grammatical and the lexical subsystems (as described by Talmy 2000, 24ff). This is due to its current position on the Verb-to-TAM (tense-aspect-modality) chain as part of its grammaticalization process (see Heine 1993, 53-70, particularly). Heine $(1993,58)$ characterizes the historical process of grammaticalization by seven overall stages (the Verb-to-TAM chain), denoted by A to $G$ starting from the less grammaticalized units, based on the matrix of four parameters. The Hungarian auxiliary is partly restricted in its conceptual potential as it can only designate a process in a distilled, desemantized way, via tense and modality. On the other hand, it also preserves part of its conceptual potential as certain facets of a temporal event structure or the participants are represented schematically; for instance, in the force-dynamic relations expressed by deontic modal auxiliaries.

Acta Linguistica Hungarica 57, 2010 
Prototypical Hungarian auxiliaries are situated at stages C, D or E of Heine's grammaticalization chain. My assessment is that a typical member of the class displays the following fundamental properties:

- it expresses a temporal relation with a specific profile, on a high level of abstraction;

- it profiles tense (only future) or modality (also aspect, but only rarely);

- the temporal relation is construed in a sequential fashion and the trajector is profiled within the semantic structure of the auxiliary;

- semantically it is dependent: it has an elaboration site for the event structure, and also one for the schematic trajector;

- the auxiliary status of the linguistic items involved is the result of cognitive processes in the context of grammaticalization;

- central auxiliaries can function as full lexical verbs as well.

Hungarian auxiliaries occupy diverse domains on the Verb-to-TAM chain. They also vary in terms of whether or not they can be inflected for tense (present vs. past), that is, whether or not they can be grounded in this respect.

Heine's Verb-to-TAM chain (with the overall stages named A to G) is the cumulative result of four partially overlapping chains, each relating to a different aspect of linguistic behaviour (cf. Heine 1993, 54). Desemantization concerns semantic developments, while decategorization is linked to morphosyntactic, cliticization to morphophonological, and erosion to phonetic, changes. Each chain has its own stages, named numerically from I to III (or $\mathrm{V}$ in the case of decategorization) reflecting ever higher degrees of grammaticalization. On these chains, Hungarian auxiliaries can be described as follows.

- desemantization: the content of the event schema turns into a more abstract content (stage II);

- decategorization: the verbs functioning as auxiliaries have lost many of their syntactic and semantic properties: the complement is an infinitive, they have no nouns as complements, they are not negated separately and do not occur independently of the infinitive, except in the case of some sentence adverbials (stages II, III, IV);

- cliticization: one simple phrase (a looser or tighter unit), with one expression of tense etc. (stage I or II);

- erosion: all auxiliaries have their full phonological form (only kellene 'should' has a shortened form kéne; stage I). 
Taking the properties enumerated above as fundamental, the following auxiliaries can be regarded as central ones (the list is not meant to be exhaustive): tud 'can', bir 'be able to', akar 'want', fog 'will, shall', kell 'have to, must', lehet 'may'. Van 'be' is limited in its use with infinitives.

Virtually all auxiliaries are polysemic, and all have main verb (lexical verb) meanings, too. In what follows, I illustrate this point by three verb/auxiliary pairs, listing only the semantically most important and/or historically earliest meanings (cf. Benkő 1967, 934; 1970, 343; 1976, 995). In all the three cases the first examples demonstrate the main verb use, the second examples the auxiliary use.

fog 'will, shall': 1. grasp, hold, take, catch 2. will, shall 3. take prisoner 4. conceive 5. perceive 6. have an effect on, etc. It is of Ugric origin, with a vast network of derivatives from fogó 'pincers' to fogalom 'concept'. The auxiliary function of $f o g$ is quite far from the original lexical meaning, the desemantization process has reached a high level of abstraction:

(13) Zsuzsa a lánya kezét fogja.

Susan the girl-poss hand-poss-acc hold-pres.ind.3sg.def

'Susan is holding her daughter's hand.'

(14) Zsuzsa Németországban fog dolgozni.

Susan Germany-iness will.3sg work-inf

'Susan will work in Germany.'

kell 'must, have to': 1 . be needed, be necessary 2 . like something, somebody, enjoy 3 . must, have to 4 . be advisable, be expedient 5 . be probable 6 . be inevitable, be unavoidable. It is of Finno-Ugric origin, with meaning 1 . The auxiliary function of kell is quite close to the original lexical meaning, the desemantization process has reached only a lower level of abstraction:

(15) Pistinek a zöld alma kell.

Steve-dat the green apple-nom need.pres.ind.3sg

'Steve wants the green apple.'

(16) Pistinek indulnia kell.

Steve-dat leave-inf-3sg must.pres.ind.3sg

'Steve must leave.'

tud 'can, be able to': 1 . know 2. can, be able to 3 . be determined, decided 4. know somebody as a personality 5 . be competent in something 6 . be 
convinced of something 7 . suspect 8 . suppose 9. speak a language, etc. It is of Uralic origin, with the reconstructed form *tumte- 'touch, finger, feel' (see e.g., Finnish tuntea 'observe, feel, know, understand, recognize'). The auxiliary function of $t u d$ is fairly close to the original lexical meaning, the desemantization process has reached only a lower level of abstraction:

(17) P
Péter tudja
a leckét.
Peter know-pres.ind.3sg.def the lesson-acc

'Peter knows the lesson.'

(18) Péter tud úszni.

Peter can.pres.ind.3sg swim-inf

'Peter can swim.'

It can be deduced from the above that Hungarian auxiliaries have developed mostly from verbs conceptually based on the event schemas of action, volition, and change of state (cf. Heine 1993, 31). Some of them are highly grammaticalized with strong evidence of desemantization and decategorization (e.g., fog 'will, shall'), others show a significantly lower degree of grammaticalization (e.g., akar 'want'), yet others are in between (e.g., tud 'can', lehet 'may').

\section{The Hungarian auxiliary + infinitive structure as a linguistic unit}

A considerable number of linguistic expressions form a complex structure morphologically or syntactically. These structures, such as verbal or nominal stem + inflection, adjective + noun, predicate + subject, are semantic composite structures, based on partial semantic correspondences and elaboration processes. The composite structures that are used frequently do not demand step-by-step processing, the structure is comprehended as a single unit (it is "pre-packaged", in Langacker's term). A linguistic unit is an expression whose internal morphological and syntactic structure may be transparent to the speaker and the hearer, but without the need for processing the components one by one in order to comprehend the expression as a whole.

The Hungarian auxiliary + infinitive construction may be generally regarded as a linguistic unit because in a usage event the components of the unit add up to a schematic content similar to what is represented 
by a simple finite verb. This schematic content specifies a temporal relation via sequential scanning (with an event structure), profiling tense, mood, person, number, and one or more participants, as in (19). However, the primary figure and syntactic subject is not always elaborated in the auxiliary + infinitive construction.

(19) Megyek.

go-pres.ind.1sg

'I'll go./I am leaving.'

Taking the four basic types of Hungarian auxiliary + infinitive structure introduced in section $\mathbf{3}$, their semantic structure can be described as follows:

In (20), representing type (A) of section $\mathbf{3}$, the auxiliary denotes deontic modality, and expresses an abstract temporal relation (a force dynamic relation) involving a trajector (i.e., a primary figure with topic function). The trajector is not elaborated in this case; if expressed, it is elaborated by a nominal with a dative suffix. This participant is the agonist and the original landmark in the force dynamic relation, whereas the antagonist, the source of the force, is left implicit. The infinitive denotes an event atemporally, with summary scanning, and has an elaboration site for the landmark (here a directional one, not elaborated).

(20) Menni kell.

go-inf must.pres.ind

'Everybody must leave./We must go.'

In (21), representing type (B) of section $\mathbf{3}$, the situation is similar except for the fact that the trajector and agonist is explicitly marked on the infinitive by the suffix for person and number (as noted above, these are possessive suffixes originally):

(21) Mennem kell.

go-inf.1sg must.pres.ind

'I must go.'

In (22), representing type $(\mathrm{C})$ of section $\mathbf{3}$, the auxiliary denotes future tense (formally in the present, with a full paradigm only for person and number), and profiles an abstract temporal relation involving the trajector (a primary figure with topic and subject function in the nominative case, here elaborated by Zsuzsa), while the infinitive denotes an event 
atemporally, with summary scanning, and has its landmark elaborated by Németországban 'in Germany':

(22) Zsuzsa Németországban fog dolgozni.

Susan Germany-iness will.3sg work-inf

'Susan will work in Germany.'

In (23), representing type (D) of section $\mathbf{3}$, the auxiliary denotes modality, and in this case ability (with a full paradigm for tense, mood, person and number), an abstract temporal relation involving the trajector (again in the nominative, elaborated by madár), while the infinitive denotes an event atemporally, with summary scanning and has an elaboration site for the landmark (a directional one, unelaborated):

(23) A madár tud repülni.

the bird can-pres.ind.3sg fly-inf

'Birds can fly?'

The grammatical constructions or composite structures are based on valence relations. These relations are specified by semantic correspondence, profile determinacy, conceptual and phonological autonomy and dependency, and constituency. The first two are the determining factors here.

The Hungarian auxiliary + infinitive construction is proposed to be a special type of composite structure. "A composite structure is formed by superimposing corresponding entities and merging their specifications" (Langacker 1987, 280), in other words, there are correspondences between the shared substructures. Both the auxiliary and the infinitive denote only some portion of the complex process expressed by the entire unit; their integration is obtained via correspondences. The auxiliary profiles a temporal relation without the main event, and as part of a construction profiling a process, it comprises a highly schematic substructure for event structure to be elaborated by the infinitive. The infinitive profiles an event atemporally, while its conceptual base (the associated conceptual scope) is prototypically temporality, and as part of the auxiliary + infinitive construction profiling a process, its conceptual base is to be elaborated by the auxiliary.

As complementary parts of the construction, the auxiliary profiles an abstract temporal relation as a process, while the infinitive accounts for most of the semantic content of the overall event structure. The auxiliary 
has the trajector of the complex unit as its primary schematic participant (and the landmark as the secondary participant), the infinitive has the landmark as its primary schematic participant (and the trajector as the secondary participant). The auxiliary profiles tense (future) or modality. Person and number are marked on the auxiliary, too, except in the case of "antagonist-oriented" auxiliaries (see section 9).

The composite structure inherits the profile of one component structure. For clauses, the finite verb is the profile determinant in the prototypical case. However, there are also "cases where the component structures contribute equally to the profile of the composite structure" (Langacker 1987, 291). The construction discussed here seems to be one with equal component contributions, although the auxiliary is more verblike, expressing a process. As indicated above, in Langacker's English model the leftmost verb (be, have, or the content verb) functions as profile determinant for the entire clausal head, while the modal auxiliary is the grounding predication. Hungarian differs from this structure in many respects and to a considerable degree.

Both the auxiliary and the infinitive are dependent (or semi-dependent).

As a composite structure and a linguistic unit, the Hungarian auxiliary + infinitive structure performs the semantic functions of the verb listed in section 3. It expresses a process, a temporal relationship, an energetic interaction between two participants, an event as it unfolds in time (through sequential scanning), and it is semantically dependent, functioning as the syntactic predicate of the clause.

The Hungarian auxiliary + infinitive construction shows significant variability according to grammaticalization, subjectification, and grounding. Before demonstrating the construction's variability along these lines, I briefly review some aspects of its submorphemic structure.

\section{The submorphemic structure}

As indicated above, Hungarian finite verbs are obligatorily inflected for tense, mood, person and number, and for the definite or indefinite status of the object in the case of transitive verbs. Most inflectional suffixes are complex in that they cannot be analysed into morphological segments for each listed function, one inflectional form may have one to three different functions (e.g., in olvas 'read' $+o k$ the affix accounts for 1st person singular, present tense, indicative mood, and an indefinite object, in contrast 
with olvas $+o$, designating 2nd person singular, with all other parameters unchanged). The system is even more complicated when no clear boundary can be determined between the stem and the suffix. These phenomena call for a network morphology model, suggested by Gundersen (2001). He assumes that there are affixes "that may show submorphemic characteristics; that is, they may display phonological and semantic connections below the level of the morph" (op.cit., 108). These submorphemic inflected forms in Hungarian are well entrenched, very frequent structures with unit status.

As with Hungarian finite verbs, the individual morphemic items and their semantic content cannot always be separated clearly in the auxiliary + infinitive structure, either. The complex semantic structure is designated not by a sequence of discrete grammatical morphemes in the composite structure, but by linguistic items with semantically complex, morphophonologically partly overlapping structures in a network fashion, with one component often simultaneously performing more than one function (cf. the infinitive with the suffix for person and number). For instance, in the construction menned kell 'you must go' menned is composed of a bound allomorph of menni 'to go', plus the suffix for 2nd person singular, while kell 'must' is inflected for present tense with a zero suffix. Properly speaking, the auxiliary does not 'add' tense or modality to the infinitive, but rather elaborates these in relation to the meaning of the verbal stem.

\section{Variability of subjectification and grounding for modality}

In addition to the general semantic factors presented in the previous sections, there are some others that are important for the functioning of the Hungarian auxiliary + infinitive construction. These factors include (i) the degree of intensity at which the eventhood is profiled, (ii) the degree of intensity at which the event structure is profiled temporally, and (iii) variability of subjectification and grounding for modality. The focus of this section is on the third of these, which has the most direct bearing on the general description of the construction. Temporal and modal grounding is performed in diverse ways either by the auxiliary or the infinitive. This variability is not merely a morphosyntactic or morphophonological phenomenon, it also contributes to the semantics of the overall unit and even the clause. 
(24) (a) Fog futni.
will.pres.3sg run-inf
'He will run.'

(b) Tud futni. can.pres.3sg run-inf 'He can run.'

Fogok futni. shall.pres.1sg run-inf 'I shall run.'

Tudok futni. can.pres.1sg run-inf 'I can run.'

(25) (a) Lehet futni.

Lehet futnia.

may.pres run-inf may.pres run-inf-3sg 'It is possible to run.' 'He may run.'

(b) Kell futni.

Kell futnom.

must.pres run-inf must.pres run-inf-1sg 'It is necessary to run.' 'I must run.'

(c) Pistának mennie kell. Steve-dat go-inf-1sg must.pres 'Steve must go.'

As can be seen in the examples, person and number are marked by the auxiliary in the sentences of (24), while the same function is performed by the infinitive in the sentences of (25). This means that the primary figure of the complex structure is profiled by a suffix on the auxiliary in (24), and it is profiled by a suffix on the infinitive in (25). In the case of (24), where person and number are marked by the auxiliary, the volitional and energy source (the potency source) is the primary figure, the acting agent. By contrast, in (25), where the infinitive is inflected for person and number, the volitional and energy source is another entity, the antagonist within the force dynamic substructure of the modal auxiliary, although this component has no morphosyntactic signifier in the clause (for force dynamics, see Talmy 2000, 409-70). The dative component in $(25 \mathrm{c})$ indicates that the agonist (the forced actor) is different from the antagonist, the outer force.

The prototypical and historically earlier schemas can be characterized as follows. In the structure with an inflected auxiliary, the agent (the conceptualized grammatical subject) and her/his energy source are construed objectively, and the process is related to the subjectively conceptualized ground, the speaker in particular by the modal. An atemporal event structure is made processual and related to the ground with respect to the reality or possibility of the agent's own potency, in the view of the speaker. (This is only one function of the Hungarian modal, the other one 
is imposing processuality on the composite structure.) The accomplishment of the process depends on the potency of the agent (the agonist). The speaker is not part of the objectively expressed scene.

In the structure with an inflected infinitive, the agent is construed objectively, but faces another source of potency, the antagonist. The agent is the source of energy for accomplishing the event represented by the infinitive, but at the same time $\mathrm{s} /$ he is the target of another force, the potency of an antagonist, imposing conditions on the completion of that event. The modal is construed objectively inasmuch as it represents the potency of the antagonist within the scene on stage. On the other hand, it is related subjectively to the ground, namely to the antagonist. The antagonist itself is not part of the scene, it is represented in the grammaticalized semantic structure of the modal. It cannot be identified exactly in every case, it may be the speaker, but it may be any other source of potency from a person to social norms, expectations, or any natural force.

Naturally enough, new types have also evolved from the patterns just described, maintaining their morphological characteristics but not necessarily their semantic ones (the relation of this distinction to the agent-oriented and speaker-oriented modals of Bybee (1985, 166-9), and to narrow and wide scope readings suggested by Pelyvás (2006), needs further research). Since the deontic auxiliaries kell 'have to, must' and lehet 'may' have acquired epistemic meanings, and also fog 'will, shall' is also used in deontic senses (e.g., for obligation), all preserving their morphological features, the conceptual basis for the distribution is not simply the deontic/epistemic distinction by default. Rather, this system based on the distinction between "agonist-oriented" and "antagonist-oriented" modals has developed into a more complex one, with real epistemic meanings, mostly derived historically from deontic ones, with no limitation to "antagonist-oriented" modals. It is reasonable to suggest a gradual view in the analysis of the Hungarian modals in the auxiliary + infinitive construction (cf. Mortelmans 2006, Pelyvás 2006).

Consequently, prototypical instantiations of the "agonist-oriented" type of modals function as grounding predications, while their "antagonist-oriented" counterparts only as attenuated ones; i.e., these modals are partly profiled within the objective scene. (This analysis shares certain assumptions with Pelyvás 2006 and Goossens 1996 while departing from Langacker's view). The real grounding status of the modals in use is also affected by the degree of their gramaticalization: the lower the degree of grammaticalization, the less a modal can function as a ground- 
ing element. However, this variation does not seem to correlate with the agonist-oriented vs. antagonist-oriented distinction; in both groups there are auxiliaries at both higher and lower levels of grammaticalization. For example, within the agonist-oriented class, fog 'will, shall' shows a higher level of grammaticalization (and relatedly, an increased capacity as a grounding element) than tud 'be able to'.

\section{Summary}

The goal of the present paper has been to outline the cognitive semantics of the Hungarian auxiliary + infinitive construction in a cognitive linguistic framework. The Hungarian auxiliary + infinitive construction is a linguistic unit representing one way of construing a process. It is a special type of composite semantic structure that expresses the semantic function of the finite verb in a clause, although in a morphosyntactically more complex and semantically more explicit way. The auxiliary profiles a process, an abstract temporal relation, and (future) tense or modality, while the infinitive accounts for most of the semantic content of the overall event structure. The two schematic participants trajector and landmark are represented as shared by the two components, although the trajector is profiled first by the auxiliary, and the landmark by the infinitive. This construction is similar to the finite verb, although the event structure, the eventhood and the schematic participants are not always elaborated to the degree they are in the case of a finite verb. Tense is denoted in a restricted way, and the use of modal auxiliaries is related to force dynamic relations.

Both component structures contribute equally to the profile of the construction (the composite structure), in a complementary way, in contrast with a prototypical composite structure. The Hungarian auxiliary serves the functions of imposing temporality on a non-temporal infinitive, and also that of the grounding predication, calling for a minor departure from Langacker's English model. The Hungarian grounding predication (the auxiliary) and its head (the infinitive) do not belong to the same grammatical class, only the auxiliary + infinitive composite structure construes a process temporally. Besides the deontic/epistemic distinction, a further important parameter of variation (cross-cutting the former) is between "agonist-oriented" and "antagonist-oriented" modals. Just like the semantic functions of the auxiliaries, subjectification and grounding also show gradual characteristics.

Acta Linguistica Hungarica 57, 2010 


\section{References}

Anderson, Gregory D. S. 2006. Auxiliary verb constructions. Oxford University Press, Oxford.

Athanasiadou, Angeliki-Costas Canakis-Bert Cornillie (eds) 2006. Subjectification. Various paths to subjectivity. Mouton de Gruyter, Berlin \& New York.

Barlow, Michael-Suzanne Kemmer 2000. Introduction: A usage-based conception of language. In: Michael Barlow-Suzanne Kemmer (eds): Usage-based models of language, vii-xxviii. CSLI Publications, Stanford.

Benkő, Loránd (ed.) 1967. A magyar nyelv történeti-etimológiai szótára I [Etymological-historical dictionary of the Hungarian language 1]. Akadémiai Kiadó.

Benkő, Loránd (ed.) 1970. A magyar nyelv történeti-etimológiai szótára II [Etymological-historical dictionary of the Hungarian language 2]. Akadémiai Kiadó.

Benkő, Loránd (ed.) 1976. A magyar nyelv történeti-etimológiai szótára III [Etymological-historical dictionary of the Hungarian language 3]. Akadémiai Kiadó.

Bybee, Joan L. 1985. Morphology. A study of the relation between meaning and form. John Benjamins, Amsterdam \& Philadelphia.

É. Kiss, Katalin 2002. The syntax of Hungarian. Cambridge University Press, Cambridge.

É. Kiss, Katalin 2004. Parallel strategies of verbal complex formation in Hungarian and West-Germanic? In: Katalin É. Kiss - Henk van Riemsdijk (eds): Verb clusters. A Study of Hungarian, German and Dutch, 335-58. John Benjamins, Amsterdam \& Philadelphia.

Geeraerts, Dirk-Hubert Cuyckens (eds) 2007. The Oxford handbook of cognitive linguistics. Oxford University Press, Oxford.

Goossens, Louis 1996. English modals and functional models: A confrontation (Antwerp Papers in Linguistics 86). University of Antwerp.

Gundersen, Helge 2001. Building blocks or network relations: Problems of morphological segmentation. In: Hanne Gram Simonsen-Rolf Theil Endresen (eds): A cognitive approach to the verb: Morphological and constructional perspectives, 95-127. Mouton de Gruyter, Berlin \& New York.

Heine, Bernd 1993. Auxiliaries. Cognitive forces and grammaticalization. Oxford University Press, Oxford.

Hopper, Paul-Sandra A. Thompson 1985. The iconicity of the universal categories "noun" and "verb". In: John Haiman (ed.): Iconicity in syntax. Proceedings of Symposium on Iconicity in Syntax, Stanford, June 24-26, 1983, 151-83. John Benjamins, Amsterdam \& Philadelphia.

Kálmán C., György - László Kálmán-Ádám Nádasdy-Gábor Prószéky 1986. Hocus, focus, and verb types in Hungarian infinitive. In: Werner Abraham - Sjaak de Meij (eds): Topic, focus, and configurationality, 129-42. John Benjamins, Amsterdam.

Keszler, Borbála (ed.) 2000. Magyar grammatika [Hungarian grammar]. Budapest, Nemzeti Tankönyvkiadó.

Langacker, Ronald W. 1987. Foundations of cognitive grammar, Vol. 1: Theoretical prerequisites. Stanford University Press, Stanford.

Acta Linguistica Hungarica 57, 2010 
Langacker, Ronald W. 1991. Foundations of cognitive grammar, Vol. 2: Descriptive application. Stanford University Press, Stanford.

Langacker, Ronald W. 2006. Subjectification, grammaticization, and conceptual archetypes. In: Athanasiadou et al. (2006, 17-40).

Modrián-Horváth, Bernadett 2009. Gesichtspunkte zu einer funktionalen Typologie der ungarischen Infinitiv regierenden Hilfsverben. In: Acta Linguistica Hungarica 56 : 326-41.

Mortelmans, Tania 2006. Langacker's 'subjectification' and 'grounding': A more gradual view. In: Athanasiadou et al. (2006, 151-75).

Pelyvás, Péter 1998. A magyar segédigék és kognitív predikátumok episztemikus lehorgonyzó szerepéről [Epistemic grounding functions of Hungarian auxiliaries and cognitive predicates]. In: László Büky - Márta Maleczki (eds): A mai magyar nyelv leírásának újabb módszerei III [Recent methods in the description of Contemporary Hungarian 3], 117-32. JATEPress, Szeged.

Pelyvás, Péter 2006. Subjectification in (expressions of) epistemic modality. In: Athanasiadou et al. (2006, 121-50).

Talmy, Leonard 2000. Toward a cognitive semantics. Vol. 1: Concept structuring systems. MIT Press, Cambridge MA. 